\title{
CUESTIONES ACTUALES DE LA SINIESTRALIDAD LABORAL EN EL DERECHO PENAL ESPAÑOL: UNA VISIÓN CRÍTICA*
}

\author{
Jaime Campaner Muñoz ${ }^{* *}$
}

Universidad de las Islas Beleares, España

\section{INTRODUCCIÓN}

Son muchas las cuestiones que inevitablemente surgen cuando se produce un accidente de trabajo y muchas las jurisdicciones que pueden tener voz en el siniestro. Esta ponencia tiene por objeto explicar las eventuales repercusiones penales del siniestro laboral. No obstante, por razones de tiempo únicamente trataremos las cuestiones que hemos considerado de mayor actualidad y enjundia jurídica.

\section{ASPECTOS PROCESALES DE LA SINIESTRALIDAD LABORAL: LA REITERADA Y SISTEMÁTICA INOBSERVANCIA DEL ARTÍCULO 3 DEL R.D. 5/2000, DE 4 DE AGOSTO, Y LA DESACERTADA DOCTRINA CONSTITUCIONAL SOBRE EL NON BIS IN IDEM}

En esta ponencia no se va a distinguir estrictamente entre aspectos procesales y sustantivos de la siniestralidad laboral, debido a que, sobre todo en esta materia, en ocasiones se trata de una distinción imposible (por ejemplo, la presunción de inocencia como regla de juicio -artículo 24.2 de la Constitución- se entremezcla con el respeto al principio de culpabilidad consagrado en el artículo 5 del Código Penal). No obstante, existe un aspecto procesal que sí merece un tratamiento autónomo y diferenciado. Se trata de la inexistencia de un reiteradamente inobservado precepto, cual es el artículo 3 del R.D. $2 / 2000$, de 4 de agosto, por el que se aprueba el texto refundido de la Ley sobre infracciones y sanciones en el orden social.

El expresado precepto reza del modo que sigue:

"1. No podrán sancionarse los hechos que hayan sido sancionados penal o administrativamente, en los casos en que se aprecie identidad de sujeto, de hecho y de fundamento.

2. En los supuestos en que las infracciones pudieran ser constitutivas de ilícito penal, la Administración pasará el tanto de culpa al órgano judicial competente o al Ministerio Fiscal y se abstendrá de seguir el procedimiento sancionador mientras la autoridad judicial no dicte

\footnotetext{
* Este trabajo coincide en esencia con la ponencia presentada el pasado 26 de febrero en el III Foro Social Aranzadi Baleares 2015, celebrado en Palma de Mallorca del 29 de enero al 26 de noviembre de 2015, bajo el título "La responsabilidad penal derivada de accidente de trabajo. Aspectos procesales y sustantivos".

** Doctor en Derecho por la Universidad Complutense de Madrid. Profesor asociado de Derecho Procesal y Penal Universidad de las Islas Baleares (España). Abogado. Contacto: jmc@valdivia-campaner.com
} 
sentencia firme o resolución que ponga fin al procedimiento o mientras el Ministerio Fiscal no comunique la improcedencia de iniciar o proseguir actuaciones.

3. De no haberse estimado la existencia de ilícito penal, o en el caso de haberse dictado resolución de otro tipo que ponga fin al procedimiento penal, la Administración continuará el expediente sancionador en base a los hechos que los Tribunales hayan considerado probados.

4. La comunicación del tanto de culpa al órgano judicial o al Ministerio Fiscal o el inicio de actuaciones por parte de éstos, no afectará al inmediato cumplimiento de las medidas de paralización de trabajos adoptadas en los casos de riesgo grave e inminente para la seguridad o salud del trabajador, a la efectividad de los requerimientos de subsanación formulados, ni a los expedientes sancionadores sin conexión directa con los que sean objeto de las eventuales actuaciones jurisdiccionales del orden penal".

Pese a la claridad del precepto, en la práctica se viene incumpliendo de modo reiterado y sistemático, de tal manera que por un mismo accidente laboral conviven un proceso penal y un procedimiento administrativo sancionador, finalizando en primer lugar este último.

Pudiera pensarse que, de darse esta situación, lo habitual es que los órganos del orden jurisdiccional penal apliquen la solución que adoptó la Sección $3^{\text {a }}$ de la Audiencia Provincial de Jaén en su Sentencia de 19 de febrero de 2003, en un supuesto de delito urbanístico: entender que la condena en la instancia entraña una vulneración del principio non bis in idem, ya que la conducta del acusado había sido ya sancionada en vía administrativa, lo cual suponía duplicidad de sanciones, existiendo identidad de sujeto, hecho y fundamento, $y$, por tanto, se vulneraba el principio de legalidad en materia penal y sancionadora. O la solución adoptada por la Sección $1^{\text {a }}$ de esa misma Audiencia Provincial en su Sentencia de 30 de octubre de 2007 en un caso -esta vez sí- relativo a un delito contra la seguridad de los trabajadores: absolver del expresado delito al apreciar la ya indicada triple identidad en un supuesto de falta de medidas de seguridad en una obra. No obstante, estas dos resoluciones constituyen excepciones a las decisiones de los órganos jurisdiccionales a lo largo y ancho de nuestro territorio nacional. Ni se paraliza el procedimiento administrativo sancionador mientras se tramita el proceso penal ni en éste se aprecia cosa juzgada cuando, pese al incumplimiento de la Administración consistente en la no paralización del procedimiento sancionador e imposición efectiva de sanción, se acusa por los mismos hechos a los mismos sujetos infractores.

No admite, desde luego, discusión la preferencia de la jurisdicción penal sobre la administrativa, que ya fue proclamada por la STC núm. 77/1983, doctrina que obliga a la Administración Pública a suspender las actuaciones, hasta tanto recaiga sentencia penal firme, cuando el hecho sea objeto de un procedimiento penal. Dicha dualidad sancionadora proscrita, que, en un principio, el TC limitaba a los supuestos de imposición de sanciones penales (SSTC núm. 159/1985, 154/1990 y 204/1996) o administrativas entre sí, pero no a la concurrencia mixta de sanciones penales y administrativas (STC núm. 154/1990), fue ampliada, a partir de la importante STC núm. 177/1999 (cuya doctrina fue ratificada por el Pleno en la STC núm. 2/2003), al concurso aparente de leyes, penales y administrativas, sobre un mismo hecho.

Pero, en esta materia, como advierte la doctrina más autorizada, las diferencias con la doctrina del Tribunal Europeo de Derechos Humanos siguen permaneciendo notables, pues, como reconoce la STC 2/2003, hasta esa fecha el Tribunal Constitucional: 
"Sólo ha reconocido de manera expresa autonomía al derecho a no ser sometido a un doble procedimiento sancionador cuando se trata de un doble proceso penal (STC 159/1987, de 26 de octubre; ATC 1001/1987, de 16 de septiembre), de modo que la mera coexistencia de procedimientos sancionadores --administrativo y penal-- que no ocasiona una doble sanción no ha adquirido relevancia constitucional en el marco de este derecho (STC 98/1989, de 1 de junio; AATC 600/1987, de 20 de mayo; 413/1990, de 26 de noviembre)".

Para mayor escarnio, separándose de la doctrina del Tribunal Europeo de Derechos Humanos, el TC ha asentado la tesis de la "compensación" de condenas administrativas y penales. Así, en la STC núm. 105/2001 desestimó un recurso de amparo en el que la Administración no respetó el principio de preferencia de la jurisdicción penal y dictó una sanción administrativa, pero posteriormente el Tribunal penal tomó en cuenta el cumplimiento de esta sanción para determinar la cuantía de la pena, doctrina que, como solución superadora del non bis in idem, ha recibido su refrendo por la STC núm. 2/2003, en la que se afirma que, en tal caso, no existe infracción de dicho principio, de suerte que "no basta la mera declaración de imposición de la sanción, si se procede a su descuento".

Como se ha avanzado, el Tribunal Europeo de Derechos Humanos considera contrario a dicha prohibición la sola existencia de doble incriminación, penal y administrativa, concluyendo que se produce infracción del non bis in idem tanto cuando un mismo hecho recibe una duplicidad de sanciones penales o administrativas entre sí como cuando ese mismo hecho es objeto de una doble incriminación que desemboca en la doble imposición de una sanción administrativa y de otra condena penal.

Esta doctrina, por lo demás, como ha destacado GIMENO SENDRA, se manifiesta coherente con la naturaleza del objeto del proceso penal, el cual no puede diferir del administrativo sancionador. El objeto de ambos procedimientos ha de ser, sobre todo, el hecho histórico o natural (SCHMIDT o ROXIN, entre otros), entendido, tal y como afirma ROXIN, como "una unidad según el concepto de la vida".

Luego, a los efectos de la determinación de la triple identidad del hecho, a la que se refiere el artículo 3 del R.D. 5/2000 ("identidad de sujeto, de hecho y de fundamento"), debiera entenderse el "hecho histórico" cometido por una persona determinada y subsumible en tipos penales o administrativos de carácter homogéneo.

Cuestión distinta es que este peligro produzca un resultado lesivo, en cuyo caso, como se verá más adelante, cabe plantearse la concurrencia de una infracción penal de resultado (homicidio o lesiones dolosas), pero nunca un delito de peligro como lo son los delitos contra la seguridad de los trabajadores.

\section{LA RESPONSABILIDAD PENAL DERIVADA DE LA SINIESTRALIDAD LABORAL}

\subsection{Tipologías delictivas}

Lo primero que debe tenerse presente es que un accidente laboral puede comportar, en su caso, la apreciación de más de un delito ( $\mathrm{e}$ incluso falta). Como veremos a continuación, existen delitos de peligro (artículos 316 y 317 del Código Penal) y delitos -y faltas- de resultado (artículos 142, 152 y 621 del Código Penal). Veámoslos sucintamente por separado, para, a continuación, analizar su posible relación, no sin antes advertir el carácter de norma penal en blanco de los artículos 316 y 
Jaime Campaner Muñoz / Cuestiones actuales de la siniestralidad laboral en el derecho penal español: una visión crítica

317, de suerte que remiten parte del supuesto de hecho del tipo penal a la normativa extrapenal relativa a la prevención de riesgos laborales, lo que ha planteado dudas acerca de su constitucionalidad por infracción del principio de legalidad penal (artículo 25.1 de la Constitución Española), tesis que se vería seriamente reforzada por la extenuante, heterogénea y dispersa normativa laboral integradora del tipo penal, que, en muchas ocasiones, ni siquiera ostenta rango de ley.

\subsubsection{Delitos de peligro: los tipos de los artículos 316 y 317 del Código Penal}

El artículo 316 prevé el castigo de quienes, "con infracción de las normas de prevención de riesgos laborales y estando legalmente obligados, no faciliten los medios necesarios para que los trabajadores desempeñen su actividad con las medidas de seguridad e higiene adecuadas, de forma que pongan así en peligro grave su vida, salud o integridad física".

Se requiere, por tanto, en primer lugar, la infracción de normas de prevención de riesgos laborales que obliguen a facilitar los medios necesarios para que los trabajadores desempeñen su actividad con las medidas de seguridad e higiene adecuadas (1). Dicha infracción debe ser cometida, según dispone el mismo precepto, por quienes estén obligados legalmente (2), siendo preciso, como resultado de aquella infracción omisiva, la puesta en peligro grave de la vida, salud o integridad física de los trabajadores (3).

Para condenar a cualquier persona por la comisión del delito previsto en el artículo 316 será necesario, en fin, probar la existencia de la mentada obligación legal, además, por supuesto, de la consiguiente infracción del deber de facilitar los medios precisos para garantizar que los trabajadores desempeñan su actividad con las medidas de seguridad e higiene adecuadas.

Configurado el artículo $316 \mathrm{CP}$ como norma penal en blanco, resulta obligado establecer, ante todo, cuáles son las normas de prevención de riesgos laborales infringidas así como determinar quién estaba concretamente obligado a observarlas.

El delito tipificado en el artículo $316 \mathrm{CP}$ es un delito doloso, hallándose penada de modo más leve (pena inferior en grado) la comisión imprudente del mismo comportamiento típico en el artículo 317 CP. Afirmar que una persona es responsable en concepto de autor de dicho delito exige probar, por tanto, no sólo la concurrencia de los elementos propios del tipo objetivo, esto es, la infracción de normas de prevención de riesgos laborales que obliguen a facilitar los medios necesarios para que los trabajadores desempeñen su actividad con las medidas de seguridad e higiene adecuadas (1), la obligación legal subjetiva correspondiente (2), y, como resultado de aquella infracción omisiva, la puesta en peligro grave de la vida, salud o integridad física de los trabajadores (3), sino también el dolo de quien es considerado autor, esto es, el conocimiento de la existencia de aquella infracción de normas de prevención, de la obligación legal que le vincula particularmente y de la producción, con ello, de una grave puesta en peligro de la vida, salud o integridad física de los trabajadores.

Como ha tenido ocasión de señalar la Sala Segunda del Tribunal Supremo en su Sentencia núm. 1233/2002, de 29 de julio, no basta para la integración del tipo penal cualquier infracción de normas de seguridad, porque esto extendería indebidamente la respuesta penal en niveles incompatibles con el principio de mínima intervención y de seguridad jurídica. La integración del tipo penal con la normativa de la prevención de riesgos laborales sólo debe ser en relación con la infracción de los más graves preceptos cuya omisión es capaz de generar un grave peligro. Se está, en consecuencia, ante una infracción de una norma de seguridad que se ha reconvertido en tipo penal por la mayor lesividad que aquella infracción conlleva para el bien jurídico de la vida, salud o integridad del colectivo de trabajadores. 
No puede perderse de vista que la gravedad va dirigida al peligro y no a la infracción de las normativa de prevención, esto es, para poder afirmar que concurren desde el punto de vista objetivo los elementos del tipo deberá apreciarse un intenso peligro para la vida, la salud o la integridad de los trabajadores.

\subsubsection{Infracciones penales de resultado: lesiones y homicidio imprudente de los artículos 142, 152 y 621 del Código Penal}

El artículo 142 del Código Penal castiga con pena de prisión al que por imprudencia grave causare la muerte de otro, mientras que el artículo 621.2 del mismo cuerpo legal castiga como autor de falta de homicidio por imprudencia al que la causare por imprudencia leve.

Por su parte, el artículo 152 del Código Penal castiga como reo de un delito de lesiones por imprudencia al que, por imprudencia grave, causare alguna de las lesiones previstas en los artículos anteriores (artículo 147.1, 149 y 150 del Código Penal, por orden de gravedad), mientras que los apartados $1^{\circ}$ y $3^{\circ}$ del artículo 621 prevén el castigo de quien por imprudencia grave cause las lesiones de menor gravedad previstas en los artículos 147.2, y de quien por imprudencia leve cause cualquier otra lesión constitutiva de delito.

La omisión de la mera diligencia exigible dará lugar a la imprudencia leve, mientras que se calificará como grave cuando la diligencia omitida sea la mínima exigible, la indispensable o elemental, todo ello en función de las circunstancias del caso. Así pues, como han señalado, entre otras muchas, las SSTS núm. 282/2005, de 4 de marzo y 186/2009, de 27 de febrero, la diferencia entre la imprudencia grave y la leve se encuentra en la importancia del deber omitido en función de las circunstancias del caso, debiendo tener en cuenta a estos efectos el valor de los bienes afectados y las posibilidades mayores o menores de que se produzca el resultado, por un lado, y por otro la valoración social del riesgo, pues el ámbito concreto de actuación puede autorizar algunos particulares niveles de riesgo.

Por último, la jurisprudencia se ha encargado de señalar que la imprudencia leve consiste en la ausencia del deber de diligencia esperable de las personas precavidas o cuidadosas (STS núm. $186 / 2009$, ya citada).

\subsection{CONCURSOS ENTRE LAS DIVERSAS TIPOLOGÍAS DELICTIVAS}

La apreciación del delito previsto en el artículo $316 \mathrm{CP}$ (materialmente una imprudencia elevada a la categoría de delito autónomo, técnicamente doloso, "pese a la ausencia de resultado") no implica la calificación de los posibles resultados que se hubieran producido como constitutivos de delito de homicidio o lesiones imprudentes, pues también es posible estimar cometida una falta por no estimarse grave la imprudencia cometida.

Además, conviene no perder de vista que al no exigir el Código Penal (artículos 316 y siguientes) la causación de un concreto resultado lesivo que se traduzca en la muerte o la lesión del trabajador, de producirse éste debería castigarse también por el resultado (delito de homicidio o lesiones imprudentes), salvo que el peligro derivado del incumplimiento del sujeto activo sólo afectaran al trabajador fallecido o lesionado, en cuyo caso, el delito de resultado absorbería al precedente delito de peligro (artículo 8.3 CP); sin embargo, cuando como consecuencia del incumplimiento se haya puesto en peligro la vida o la salud de otros trabajadores, se daría un concurso ideal de delitos a penar conforme a las reglas previstas en el artículo 77 del Código Penal. 


\subsection{LA RESPONSABILIDAD CRIMINAL DEL EMPRESARIO DERIVADA DEL ACCIDENTE DE TRABAJO}

El accidente laboral sitúa en el punto de mira a un amplio abanico de sujetos que habrían actuado - o podrían haber actuado- por acción u omisión de modo imprudente. Determinar quién es penalmente responsable del accidente puede convertirse en una tarea sumamente compleja y en ocasiones imposible, pero no por ello debería recurrirse -como con frecuencia se recurre- al fácil recurso de dirigir la imputación y, en ulterior momento procesal, la acusación contra el empresario.

El artículo 318 del Código Penal señala que:

"Cuando los hechos previstos en los artículos de este título se atribuyeran a personas jurídicas, se impondrá la pena señalada a los administradores o encargados del servicio que hayan sido responsables de los mismos y a quienes, conociéndolos y pudiendo remediarlo, no hubieran adoptado medidas para ello".

Por su parte, el artículo 31 del expresado cuerpo legal establece que:

"El que actúe como administrador de hecho o de derecho de una persona jurídica, o en nombre o representación legal o voluntaria de otro, responderá personalmente, aunque no concurran en él las condiciones, cualidades o relaciones que la correspondiente fi gura de delito o falta requiera para poder ser sujeto activo del mismo, si tales circunstancias se dan en la entidad o persona en cuyo nombre o representación obre".

Los criterios de atribución de responsabilidad criminal que se utilicen deben respetar escrupulosamente las exigencias del principio de culpabilidad, consagrado en el artículo 5 del Código Penal y que, en suma, supone la imposibilidad de imposición de pena alguna si no existe dolo o imprudencia en el plano subjetivo, esto es, la proscripción de la responsabilidad puramente objetiva.

Por tanto, tan sólo debe imputarse, acusarse y, en su caso, condenarse a los sujetos personalmente responsables de cada accidente laboral, sin que tengan por qué coincidir en todos los supuestos, $o$, dicho de otro modo, sin que exista una hoja de ruta estática para la atribución de la responsabilidad penal en el ámbito de la siniestralidad laboral. No obstante, la práctica ha impuesto una poco o nada garantista, pero muy efectiva desde el punto de vista represivo, hoja de ruta consistente en imputar, acusar y, en muchas ocasiones condenar al representante, administrador y/o gerente de la empresa en cuyo seno se produce el accidente, trasladando sin contemplaciones y de modo automático la responsabilidad penal a la persona que ostenta alguna de las expresadas condiciones por el mero hecho de ostentarlas, con clara infracción del principio de culpabilidad. Y todo ello a pesar de que la Sala Segunda viene repitiendo como un mantra que no cabe confundir:

"La culpabilidad penal, que siempre es subjetiva y personal, como dependiente siempre de las facultades anímicas del sujeto activo, con otro tipo de responsabilidades (laborales, civiles, administrativas, etc.) cuyo ámbito jurisdiccional puede revestir $y$, de hecho reviste, por la complejidad de las actividades que la vida del trabajo y de convivencia social reportan, un desarrollo más objetivo y amplio, dentro del cual cabe instar y acoger obligaciones de 
naturaleza patrimonial y carácter indemnizatorio que se excluyen de la restringida jurisdicción criminal" (STS de 2 de noviembre de 1976).

A este respecto, las Sentencias del Tribunal Constitucional números 150/1989 y 253/1993 destacan que ninguna cláusula general del estilo de la del art. 15 bis del anterior Código Penal (actual art. 31), puede significar excepción alguna de esos principios culpabilísticos para representantes de personas jurídicas: afirmando finalmente: "si ello puede ser válido, en algunos supuestos, en el ámbito de la responsabilidad civil patrimonial por daños, es incompatible con los principios del Derecho Penal y, desde luego, con los derechos reconocidos en el art. 24.2 de la Constitución, tanto con el principio de culpabilidad conforme se deriva de las exigencias de la Constitución, como con el derecho fundamental a la presunción de inocencia".

La jurisprudencia menor también ha declarado en repetidas ocasiones que ser representante legal de una empresa no es título suficiente para la atribución de responsabilidades específicas relacionadas con el control del riesgo atinente a la realización de una maniobra (Auto de la Audiencia Provincial de Madrid, Sección $15^{\mathrm{a}}$, de 20 de febrero de 2006). Resultan diáfanas las enseñanzas contenidas en el Auto de la Audiencia Provincial de Madrid, Sección 15a , de 31 de enero de 2000, cuando sostiene que:

"Es importante subrayar que el mero hecho de ser administrador o representante de una sociedad no quiere decir que haya de responderse penalmente de todo lo que ocurra dentro de su ámbito laboral. Pues el art. 15 bis del C. Penal de 1973 (art. 31 del Código actual) no constituye un cheque en blanco para atribuir la responsabilidad penal de todas las acciones ilícitas ocurridas en el ámbito de una empresa a sus administradores por el mero hecho de serlo, sino que se trata de un precepto que vino a cubrir las lagunas técnico jurídicas que generaban los delitos especiales en que la condición específica exigida para la autoría se daba en las entidades pero no en sus administradores". Por ello, la expresada resolución judicial concluye que "lo importante no es averiguar quiénes eran los administradores o representante legales de las sociedades involucradas, sino que lo relevante es comprobar quiénes dentro de ellas se hallaban encargados de adoptar las medidas de seguridad y de verificar su real cumplimiento".

Por último, resulta de interés lo declarado por la Sección $2^{\mathrm{a}}$ de la Audiencia Provincial de Barcelona en su Sentencia de 18 de junio de 2002: "no se puede pretender derivar de este precepto la imposición de una responsabilidad penal por el mero hecho de ser empresario. Una tal comprensión sería contraria a los principios de un Derecho penal del hecho y nos colocaría, indefectiblemente, en la senda de un inaceptable Derecho penal de autor".

Por tanto, y recapitulando, ni toda infracción de la normativa en materia de prevención de riesgos laborales seguida de un siniestro tiene por qué ser delictiva ni debe criminalizarse al administrador, gerente y/o representante de la empresa infractora de la expresada normativa. Un modelo que descanse en la equiparación entre empresa infractora y empresario delincuente, aunque tentador y eficiente para la represión de las infracciones en esta materia, deviene claramente inconstitucional y constituye en retroceso que un Estado democrático de Derecho no puede asumir. El Estado debe lanzar un mensaje preventivo a la ciudadanía (entre la que incluimos a los empresarios): el Derecho Penal funciona y si se incumple la normativa de prevención, dándose determinados requisitos, se castiga penalmente al infractor. Pero ese mensaje no puede acabar 
mutando en el siguiente: haga lo que haga, si como consecuencia de una infracción de la normativa de prevención de riesgos laborales se produce un accidente, usted responderá penalmente por ello. Esto generaría pánico en muchos sectores de riesgo (singularmente, en el de la construcción) $y$, con ello, una paralización y/o un descenso del desarrollo económico del país, con clara incidencia en las tasas de paro, que se verían incrementadas. Esto es, paradójicamente, el sujeto objeto de protección por la norma penal (el trabajador) acabaría perjudicado.

En íntima conexión con lo anterior, existen dos situaciones muy frecuentes en la práctica que deberían servir para que el administrador, representante o gerente de la empresa no tuviera que padecer consecuencias penales en el caso de que se produjera un siniestro laboral: la delegación de funciones y la contratación de actividades ajenas a las propias de la empresa contratante. Las analizaremos a continuación.

\subsection{Delegación de funciones}

En pleno siglo XXI es difícilmente imaginable y absolutamente imposible, por motivos más que obvios, que el empresario sea quien se encargue -y, por ende, se responsabilice- personalmente de las labores de prevención y seguridad en el trabajo.

Hoy en día es razonable, eficiente y plenamente legítima la distribución de funciones y, con ella, la delegación de competencias en personas capacitadas y especialistas. Como recuerda la Sentencia del Tribunal Supremo de 26 de marzo de 1994:

"No es humanamente posible que quienes deben ejercer su posición de garante, que requiere, por su naturaleza, una distribución de funciones, puedan realizar personalmente todas las operaciones necesarias para el cumplimiento de ese deber; por ello el Ordenamiento jurídico reconoce el valor exonerante de la responsabilidad a la delegación de la posición de garante, cuando tal delegación se efectúa en personas capacitadas para la función (...)”

En cada procedimiento de trabajo cada persona debe asumir la responsabilidad que le corresponde y que le haya sido derivada en función de la distribución de tareas. Así lo expresa el Auto Audiencia Provincial de Vizcaya, Sección 6a, núm. 639/2002, de 16 de noviembre:

"La responsabilidad penal, no puede olvidarse nunca, debe referirse a una actuación dolosa o imprudente, y nunca por una determinada pertenencia a un órgano de representación o por la detentación de la titularidad formal de la empresa lo que vendría a constituir nada menos que una responsabilidad objetiva. Como conclusión de lo expuesto ha de afirmarse que no sólo el empresario estará obligado a facilitar los medios garantizadores del nivel adecuado de seguridad sino que quienes le sustituyen de la forma anteriormente descrita asumen obligaciones en nuevas posiciones de garante, siendo precisamente la normativa laboral la que impone diferentes obligaciones a quienes forman parte en el proceso de trabajo, hasta el punto de que la posición de garante no se deriva de una relación jerarquizada entre sujetos sino de su relación objetiva con los hechos."

Como declaró la Sentencia de la Sección 10 a de la Audiencia Provincial de Barcelona de 8 de septiembre de 2009: 
"Aun cuando ostenten el primer peldaño de constreñimiento, no es únicamente al empresario a quien atañe ese deber de facilitar los medios de seguridad pues basta reparar en que el propio Código Penal (artículo 318) lo extiende genéricamente a "encargados del servicio" y la ley 31/1995 establece otras graduaciones por vía de la delegación, así en su artículo 30 dispone que "en cumplimiento del deber de prevención de riesgos profesionales, el empresario designará uno o varios trabajadores para ocuparse de dicha actividad, constituirá un servicio de prevención o concertará dicho servicio con una entidad especializada ajena a la empresa".

Por tanto, el empresario que, invirtiendo las partidas económicas precisas para la dotación de formación y equipos de protección individual y colectiva para los trabajadores, delegue las labores de prevención en personas capacitadas al efecto, nunca debería responder penalmente por los eventuales accidentes que se produzcan.

\subsection{Contratación de actividades ajenas a las propias de la empresa CONTRATANTe}

La complejidad del mundo empresarial moderno y el elevado grado de especialización de las empresas obliga a contratar actividades que no son estrictamente las propias de la empresa contratante.

Configurado el artículo $316 \mathrm{CP}$ como norma penal en blanco, resulta obligado establecer, ante todo, cuáles son las normas de prevención de riesgos laborales infringidas así como determinar "quién estaba concretamente obligado a observarlas".

La práctica nos enseña que en demasiadas ocasiones poco viene importando esta circunstancia a los órganos jurisdiccionales penales, lo cual será objeto de explicación siguiendo un ejemplo real actualmente no finalizado mediante sentencia firme al haber anulado la Audiencia Provincial la primera resolución del Juzgado de lo Penal, por falta de motivación de la condena, hallándose actualmente pendiente del dictado de nueva sentencia por este último órgano jurisdiccional.

En la primera sentencia -actualmente anulada- se afirmaba que la normativa clave en la materia la constituía "la Ley de Prevención de riesgos laborales de 1995, así como el R.D. de 18 de julio de 1997", afirmándose acto seguido que "el artículo 42 de la Ley de prevención de Riesgos Laborales, al tratar el punto relativo a responsabilidades y sanciones dispone expresamente que la empresa principal responderá solidariamente con los contratistas y subcontratistas, durante el periodo de contrata, de las obligaciones impuestas por esta Ley en relación con los trabajadores que aquellos ocupen en los centros de trabajo de la empresa principal".

El citado artículo 42 de la Ley de Prevención de riesgos laborales fue derogado en el año 2000 (concretamente por la letra $\mathrm{c}$ ) del número 2 de la disposición derogatoria única del R.D. Leg. $5 / 2000,4$ agosto, por el que se aprueba el texto refundido de la Ley sobre Infracciones y Sanciones en el Orden Social), si bien la previsión en él contenida puede hallarse desde entonces, en idénticos términos, en el artículo 42 de la Ley sobre Infracciones y Sanciones en el Orden Social, cuyo tenor literal es el siguiente:

“3. La empresa principal responderá solidariamente con los contratistas y subcontratistas a que se refiere el apartado 3 del artículo 24 de la Ley de Prevención de Riesgos Laborales del cumplimiento, durante el período de la contrata, de las obligaciones impuestas por dicha Ley en relación con los trabajadores que aquéllos ocupen en los centros de trabajo de la 
empresa principal, siempre que la infracción se haya producido en el centro de trabajo de dicho empresario principal'.

Obsérvese una trascendental diferencia entre el trascrito artículo 42 de la Ley sobre Infracciones y Sanciones en el Orden Social y lo afirmado en la sentencia: "el artículo 42 de la Ley de prevención de Riesgos Laborales (...) dispone expresamente que la empresa principal responderá solidariamente con los contratistas y subcontratistas, durante el periodo de contrata, de las obligaciones impuestas por esta Ley en relación con los trabajadores que aquellos ocupen en los centros de trabajo de la empresa principal".

La sentencia omitió, como fácilmente puede apreciarse, una parte importante del contenido de dicho artículo 42, que "matiza la responsabilidad de la empresa principal", pues sólo responderá solidariamente con los contratistas y subcontratistas "a que se refiere el apartado 3 del artículo 24 de la Ley de Prevención de riesgos laborales".

Dicho artículo 24, apartado 3, rubricado "Coordinación de actividades empresariales", establece que "las empresas que contraten o subcontraten con otras la realización de obras o servicios correspondientes a la propia actividad de aquéllas y que se desarrollen en sus propios centros de trabajo deberán vigilar el cumplimiento por dichos contratistas y subcontratistas de la normativa de prevención de riesgos laborales".

En el caso que estamos tratando la denunciada omisión resulta de fundamental importancia, pues los servicios contratados por la empresa A a la empresa B no eran correspondientes a la actividad propia de A, la cual, como reconoció la propia sentencia en su relato de Hechos Probados, se dedicaba "al almacenamiento y venta de cemento en las instalaciones situadas en el Km. 6 de la carretera X". A contrató a B, como también estima probado la sentencia, "para la instalación de un tubo para la extracción del polvo en el silo". Dicho con otras palabras, A contrató (resulta incorrecto, como explicaremos después, afirmar que "subcontrató") a B para realizar trabajos de reparación y mantenimiento en la Planta de A sita en la ya indicada dirección.

¿Cómo debían articularse las relaciones entre ambas empresas? El referido artículo 24 de la Ley sobre Infracciones y Sanciones en el Orden Social establece, en su primer número, que:

"Cuando en un mismo centro de trabajo desarrollen actividades trabajadores de dos o más empresas, éstas deberán cooperar en la aplicación de la normativa sobre prevención de riesgos laborales. A tal fin, establecerán los medios de coordinación que sean necesarios en cuanto a la protección y prevención de riesgos laborales y la información sobre los mismos a sus respectivos trabajadores, en los términos previstos en el apartado 1 del artículo $18 \mathrm{de}$ esta Ley".

El mismo precepto, ahora en su segundo número, dispone que:

"El empresario titular del centro de trabajo adoptará las medidas necesarias para que aquellos otros empresarios que desarrollen actividades en su centro de trabajo reciban la información y las instrucciones adecuadas, en relación con los riesgos existentes en el centro de trabajo y con las medidas de protección y prevención correspondientes, así como sobre las medidas de emergencia a aplicar, para su traslado a sus respectivos trabajadores". 
El tercer (y referido) número de dicho artículo 24 no se conforma con exigir cooperación y coordinación entre las empresas (art. 24.1) o con requerir que el empresario titular del centro de trabajo informe al empresario contratado sobre los riesgos propios del centro de trabajo y las medidas de protección y prevención correspondientes -e, incluso, sobre las medidas de emergencia a aplicar en su caso- (art. 24.2), pues impone, además, el deber, a cargo de dicho empresario titular del centro de trabajo, de vigilar el cumplimiento por dichos contratistas (y, en su caso, subcontratistas) de la normativa de prevención de riesgos laborales, "siempre", sin embargo, como ya se ha advertido, "que las empresas contratadas (o subcontratadas) realicen obras o servicios correspondientes a la propia actividad de aquellas", circunstancia que no concurría en el caso que estamos explicando.

En cumplimiento de dichas obligaciones de cooperación, coordinación e información, la empresa A, por medio de la persona física condenada en la instancia, remitió a B, como igualmente reconoce la sentencia, su Evaluación de Riesgos, Plan de Emergencia del centro de trabajo y normas y procedimientos que debería observar B. Así, por ejemplo, era importante que B tuviera presentes los riesgos de exposición a radiaciones o a agentes químicos, biológicos o físicos, los de inhalación, contacto o ingestión de sustancias nocivas, los de incendios o explosiones, etc. Ahí terminaban, sin embargo, las obligaciones de A, empresa que no debía supervisar, por resultar totalmente lógico y por no imponerlo la normativa correspondiente, la actividad propia de la empresa $B$, que, y es preciso insistir en ello, no había sido contratada o subcontratada para realizar actividades propias de $\mathrm{A}$, es decir, de almacenamiento y venta de cemento, sino para realizar actividades de reparación y mantenimiento.

Imaginemos, por ejemplo, que el titular de un restaurante contrata a un electricista para que éste repare el aire acondicionado o el equipo eléctrico de su local o centro de trabajo. Por supuesto, deberá informarle en los términos exigidos por el artículo 24.1 y 2 de la Ley sobre Infracciones y Sanciones en el Orden Social a fin de que tenga conocimiento de los riesgos propios de dicho centro de trabajo, pero no deberá ocuparse de supervisar que el electricista, en las funciones que le son propias, y totalmente extrañas al empresario restaurador, observa las normas de prevención de riesgos laborales correspondientes.

Otro tanto sucede en el caso objeto de comentario: A contrató a B para realizar determinadas actividades ajenas o extrañas a $\mathrm{A}$ y propias, por el contrario, de $\mathrm{B}$, cumpliendo la primera de dichas empresas las obligaciones impuestas por ley en materia de prevención de riesgos laborales.

Es incorrecto afirmar, por otra parte, como ya habíamos anunciado, que A subcontrató a B. En efecto, como subcontratación se define la gestión o ejecución permanente de una función empresarial por un proveedor externo de servicios. Es común utilizar en este ámbito los términos out-tasking, esto es, externalización de tareas, que implican la delegación de una porción estrictamente delimitada del negocio a otro negocio.

Obviamente, este no era el caso en el supuesto objeto de análisis, pues A no encargó a B la gestión o ejecución permanente de funciones empresariales propias de aquélla. Además de a esta última, A (empresa contratante) contrató a otras empresas (contratistas) para realizar ciertas actividades, igualmente extrañas a la actividad de $\mathrm{A}$, como la reparación de una secadora de materiales o de las averías del motor-cinta de salida de sacos o de las luces del descargador, actividades todas ellas encargadas a $\mathrm{C}$, sin que deviniera obligación de A supervisar el cumplimiento de las normas de prevención por parte de esta última empresa en la realización de actividades que sí le eran propias $y$, por el contrario, extrañas a $\mathrm{A}$. 
Distinto sería el caso, evidentemente, si A hubiera contratado a B o a otra empresa para realizar actividades de almacenamiento o venta de cemento, esto es, si hubiera efectivamente subcontratado la gestión o ejecución de actividades propias.

La subrayada confusión entre contratar y subcontratar se hace evidente en la propia sentencia anulada cuando se refiere (como veremos inmediatamente, de forma totalmente desacertada por no resultar aplicable al caso), tras considerar clave la Ley de Prevención de Riesgos Laborales y destacar lo previsto por su (derogado) artículo 42, al Real Decreto (1267) de 24 de octubre de 1997, el cual, explica la sentencia anulada:

\begin{abstract}
"Señala que tanto contratista como subcontratistas tendrán la condición de empresarios a los efectos previstos en la normativa sobre prevención de riesgos laborales y los dos industriales están obligados a aplicar los principios de acción preventiva. Ambos empresarios son pues responsables de la ejecución correcta de las medidas preventivas fijadas en el plan de seguridad y salud en lo relativo a las obligaciones que les corresponden a ellos directamente o, en su caso, a los trabajadores autónomos por ellos contratados".
\end{abstract}

El citado Real Decreto 1267/1997, de 24 de octubre, por el que se establecen disposiciones mínimas de seguridad y de salud en las obras de construcción, es exclusivamente de aplicación, según dispone su artículo 1.1, a las obras de construcción, conteniéndose en su artículo 2 una serie de definiciones (entre ellas la de obra de construcción) entre las que se hallan las de contratista y subcontratista:

a) Contratista: la persona física o jurídica que asume contractualmente ante el promotor, con medios humanos y materiales, propios o ajenos, el compromiso de ejecutar la totalidad o parte de las obras con sujeción al proyecto y al contrato.

b) Subcontratista: la persona física o jurídica que asume contractualmente ante el contratista, empresario principal, el compromiso de realizar determinadas partes o instalaciones de la obra, con sujeción al proyecto por el que se rige su ejecución.

B fue contratada por A asumiendo contractualmente ante ésta, y no ante un contratista, determinados compromisos, por lo que denominarla subcontratista resulta absolutamente inapropiado. El mismo artículo 2 del RD 1267/1997 establece que "el contratista y el subcontratista a los que se refiere el presente Real Decreto tendrán la consideración de empresario a los efectos previstos en la normativa sobre prevención de riesgos laborales", por lo que "ambos empresarios son pues responsables de la ejecución correcta de las medidas preventivas fijadas en el plan de seguridad y salud en lo relativo a las obligaciones que les corresponden a ellos directamente o, en su caso, a los trabajadores autónomos por ellos contratado". Dicho con otros términos, "la subcontratación por parte del contratista de los servicios encargados no elimina su responsabilidad".

Todas estas reflexiones revelan, como hemos adelantado, la confusión en que incurrió el órgano a quo, determinante del fallo alcanzado, y nos han servido para desterrar la idea de que la subcontratación de una empresa elimina la responsabilidad de la contrata y, además, para discernir entre supuestos de contratación (o subcontratación) de actividades propias y ajenas a la actividad empresarial. 


\section{LA RESPONSABILIDAD PENAL DE LAS PERSONAS JURÍDICAS EN MATERIA DE SINIESTRALIDAD LABORAL: UNA OMISIÓN INCOMPRENSIBLE}

El pasado día 23 de diciembre de 2010 entró en vigor la reforma del Código Penal operada por la LO 5/2010, de 22 de junio.

Desde la aprobación, en 1995, del Código Penal vigente, nuestro texto punitivo no ha previsto más que consecuencias accesorias -nunca penas- que el Juez o Tribunal puede imponer, con carácter facultativo, a las personas jurídicas, mas siempre previa declaración de responsabilidad penal de una persona física. Se trata de una previsión, contenida en el artículo $129 \mathrm{CP}$, que ha tenido una escasísima aplicación en la práctica de nuestros Tribunales. Por tanto, en España, las personas jurídicas son (y han sido siempre) penalmente irresponsables, atribuyéndose en el artículo 31.1 C.P. la expresada responsabilidad a las personas físicas que las administran.

La Ley objeto de comentario establece una responsabilidad penal directa y autónoma de las personas jurídicas, previendo la imposición de penas gravísimas (algunas de las cuales podrán ser acordadas por el Juez de Instrucción como medida cautelar) que van desde la multa, pasando por la intervención judicial, la suspensión de actividades o la clausura temporal de establecimientos, hasta la mismísima disolución de la persona jurídica (la pena de muerte). Eso sí, adopta un numerus clausus de supuestos para la admisión de responsabilidad penal de la empresa, es decir, opta por un sistema tasado, aunque ciertamente extenso.

Existen dos hipótesis básicas para la apreciación de la responsabilidad penal de una persona jurídica (apartado $1^{\circ}$ del artículo 31 bis) y ambas presentan como común denominador la previa comisión de un delito por parte de una persona física:

1. La comisión de un delito por parte de una persona física en quien concurra la condición de representante legal o administrador de hecho o de derecho "en nombre o por cuenta" de la persona jurídica "y en su provecho".

2. La comisión del delito por parte de una persona física sometida a la autoridad de las personas mencionadas en el párrafo anterior "en el ejercicio de actividades sociales y por cuenta y en provecho" de la persona jurídica, cuando le haya sido posible a aquélla la comisión de los hechos por no haberse ejercido sobre la misma "el debido control atendidas las concretas circunstancias del caso".

En nuestra opinión, esta reforma ha roto, sin motivación alguna, con la teoría del delito confeccionada desde antiguo por la dogmática penal; concretamente con el principio de culpabilidad como proscripción de la responsabilidad puramente objetiva.

Es claro que la persona jurídica, en tanto que ficción creada por el Derecho, no actúa por sí misma sino que precisa de la acción de una persona física. Y menos aún actúa con conciencia propia y con sentido de la responsabilidad, precisamente porque tales notas únicamente son predicables de los seres humanos (en este caso, de la persona física que actúa en nombre o por cuenta de la persona jurídica). Si esto es así -que lo es-, se convendrá en que deviene absolutamente diáfana la imposibilidad de efectuar juicio alguno de culpabilidad en el sentido indicado (verificar si en el actuar del sujeto persona jurídica existió, en el plano subjetivo, dolo o imprudencia).

Los redactores de la tan traída reforma no han tenido empacho alguno en facilitar la carga de la prueba que -por elementales exigencias constitucionales-incumbe de modo inexcusable 
a la acusación, lo cual fomentará la relajación de la expresada parte procesal. Siempre habrá un culpable: la persona jurídica.

En íntima conexión con lo apuntado hasta este lugar, cabe cuestionarse muy seriamente dónde queda el derecho fundamental a la presunción de inocencia de todo acusado en un proceso penal (sea persona física o jurídica).

Lo cierto es que se cierne una espesa sombra de inconstitucionalidad sobre la regulación del estatuto penal de las personas jurídicas en la reforma objeto de comentario, en cuanto que la misma prevé fórmulas de objetivización de la responsabilidad penal de dichos entes por hechos, en puridad, ajenos.

Y estas fórmulas no son sino presunciones iuris et de iure de responsabilidad penal totalmente vedadas por las más altas instancias jurisdiccionales. Ciertamente, el Tribunal Europeo de Derechos Humanos ha admitido el establecimiento de presunciones iuris tantum contra el imputado, si bien matizando que ello será admisible siempre y cuando no rebasen los límites razonables en atención a la gravedad del asunto y, sobretodo, se preserve el derecho de defensa. Sin embargo, estas exigencias no parecen cumplirse en la regulación de la nueva responsabilidad penal de las personas jurídicas, toda vez que objetivan su responsabilidad (es decir, presumen su culpabilidad) con base en la mera relación con la persona física y el provecho que puedan haber obtenido aquellas, $o$ ante la mera imposibilidad de concretar qué persona física habría cometido el delito, 0 , incluso, ante la simple imposibilidad de dirigir el proceso contra tal persona.

Resulta inexplicable que no se haya regulado la eventual exclusión de responsabilidad penal de las personas jurídicas, como sí se ha hecho en el derecho comparado del que ha bebido el legislador español. En efecto, en el plano de la antijuricidad, no se han regulado causas de justificación propias ni le son transferibles las concurrentes en las personas físicas.

Mientras que no se han previsto circunstancias agravantes en la graduación de la responsabilidad penal de las personas jurídicas, el apartado $4^{\circ}$ del artículo 31 bis contiene un catálogo de circunstancias atenuantes de la responsabilidad criminal que se caracterizan por su carácter ex post facto, echándose en falta la inclusión de una atenuante de análoga significación a las mismas, tal y como ocurre en el caso de las atenuantes reguladas en el art. $21 \mathrm{CP}$ para las personas físicas.

No obstante, y en lo que aquí interesa, en la próxima reforma del Código Penal (BOCG de 4 de octubre de 2013), actualmente en tramitación parlamentaria, se reconoce de modo explícito de los programas de cumplimiento (compliance) como causa de exoneración de la responsabilidad criminal (en puridad, también será una obligación cuyo incumplimiento, deficiente diseño o implantación, etc., determinará la comisión de un delito, si bien, no es éste el lugar para disertar sobre esta materia - vid. nuevo art. 286 seis-). En efecto, el expresado Proyecto propone introducir en el artículo 31 bis CP una referencia a que la persona jurídica quedará exenta de responsabilidad criminal si se cumplen las siguientes condiciones:

“1. El órgano de administración ha adoptado y ejecutado con eficacia, antes de la comisión del delito, modelos de organización y gestión que incluyen las medidas de vigilancia y control idóneas para prevenir delitos de la misma naturaleza.

2. La supervisión del funcionamiento y del cumplimiento del modelo de prevención implantado ha sido confiado a un órgano de la persona jurídica con poderes autónomos de iniciativa y de control

3. Los autores individuales han cometido el delito eludiendo fraudulentamente los modelos de organización y de prevención. 
4. No se ha producido una omisión o u n ejercicio insuficiente de sus funciones de supervisión, vigilancia y control por parte del órgano.de vigilancia y control.

En los casos en los que las anteriores circunstancias solamente puedan ser objeto de acreditación parcial, esta circunstancia será valorada a los efectos de atenuación de la pena”.

El sistema propuesto, amén de resolver las críticas vertidas hasta este lugar sobre el modelo implantado en 2010 debido a la incorporación del criterio del "defecto de organización" como parámetro con el que determinar la culpabilidad de la persona jurídica, con toda seguridad, fomentará la prevención de los delitos en el seno de las empresas y sería una oportunidad de oro para reducir las tasas de siniestralidad laboral motivando al empresario lanzándole el mensaje de que con un completo programa de cumplimiento operativo ninguna responsabilidad penal podrá exigírsele. Pero decimos que "sería" una oportunidad de oro porque, incomprensiblemente, en ese numerus clausus de delitos que pueden cometer las personas jurídicas no se hallan los analizados en esta ponencia, lo cual sería tan razonable como deseable.

En efecto, a la persona jurídica no pueden atribuírsele ni el homicidio ni las lesiones imprudentes. Muchos accidentes de trabajo con estos resultados pueden deberse a una mala organización o planificación empresarial, de tal manera que el homicidio en su modalidad imprudente es uno de los delitos en los que debería admitirse la responsabilidad criminal de las personas jurídicas. Lo mismo cabe decir de las lesiones imprudentes. Ello sería coherente con la previsión del artículo $316 \mathrm{CP}$, que, como hemos visto, castiga a los que con infracción de las normas de prevención de riesgos laborales y estando legalmente obligados, no faciliten los medios necesarios para que los trabajadores desempeñen su actividad con las medidas de seguridad e higiene adecuadas, de forma que pongan así en peligro grave su vida, salud o integridad física, previéndose incluso, aparentemente -como se verá a continuación-, la responsabilidad criminal de las personas jurídicas en el artículo $318 \mathrm{CP}$. En estas circunstancias, consideramos que si el riesgo prevenido llega a concretarse en lesión de un bien jurídico la persona jurídica también debería responder penalmente, en cuanto que la lesión o el homicidio sea producto de esa deficiencia imputable a la persona jurídica.

Decíamos que aparentemente el Código Penal permite castigar penalmente a las personas jurídicas a las que se les atribuya la comisión del delito contra la seguridad de los trabajadores del artículo 316 (y 317). Sin embargo, una deficiente redacción del artículo 318 lo impide, a pesar de que reconoce la posibilidad de que "estos delitos se puedan atribuir a personas jurídicas", ya que, de modo inexplicable e inaudito, a continuación dicho precepto tan sólo prevé para tales casos consecuencias penales para sus administradores o encargados del servicio y para los entes sin personalidad jurídica (art. $129 \mathrm{CP}$ ), dejando fuera del ámbito de la autoría a los entes con personalidad jurídica. 